\title{
High-flow Nasal Cannula therapy: A feasible treatment for vulnerable older COVID-19 patients on the wards
}

Job van Steenkiste ( $\square$ jobvansteenkiste@gmail.com )

Maasstad Ziekenhuis https://orcid.org/0000-0002-5062-5397

Michael C. van Herwerden

Maasstad Ziekenhuis

Dolf Weller

Maasstad Ziekenhuis

Christiaan J. van den Bout

Maasstad Ziekenhuis

Rikje Ruiter

Maasstad Ziekenhuis

Jan G. den Hollander

Maasstad Ziekenhuis

Rachida el Moussaoui

Maasstad Ziekenhuis

Gert T. Verhoeven

Maasstad Ziekenhuis

Charlotte van Noord

Maasstad Ziekenhuis

Marinus van den Dorpel

Maasstad Ziekenhuis

Research article

Keywords: COVID-19, Intensive Care Unit, High-flow Nasal Cannula, Frailty

Posted Date: November 3rd, 2020

DOl: https://doi.org/10.21203/rs.3.rs-34470/v2

License: (c) (1) This work is licensed under a Creative Commons Attribution 4.0 International License.

Read Full License 


\section{Abstract}

Background: In the midst of the COVID-19 crisis, many frail elderly adults were admitted to our hospital with COVID-19. Some faced severe respiratory failure but were not eligible for invasive mechanical ventilation, due to frailty, functional status, comorbidity or wish of the patient. Our main objective was to investigate whether High-flow nasal cannula (HFNC) treatment on the wards could be an effective alternative treatment for these patients.

Methods: A retrospective cohort study amongst COVID-19 adult patients with respiratory failure defined as persisting hypoxemia despite maximum conventional oxygen administration requiring invasive mechanical ventilation in the Intensive Care Unit (ICU) but being treated with HFNC as they were noneligible due to frailty or wish of the patient.

Results: The study included 32 patients between March $9^{\text {th }}$ and May $1^{\text {st }}, 2020$. The median age was 79.0 years (74.5-83.0) with a median of three comorbidities (3-4) and a median Clinical Frailty Score of 4 out of 9 (3-6). The median Sp02/FiO2 Ratio was 157.5 indicating moderate ARDS. Overall survival rate in the HFNC cohort was $25 \%$. Age (80.5 (78.0-84.3) vs $69.5(65.5-74.3) \mathrm{p}=0.0040)$ and hypertension $(92 \%$ vs $25 \%, p=0.0008$ ) were correlated with mortality.

Conclusion: This study suggests that HFNC could be an effective last resort respiratory management strategy for respiratory failure in vulnerable elderly COVID-19 patients who failed on conventional high dose oxygen supply and are not eligible for invasive mechanical ventilation.

\section{Background}

At the end of December 2019, China's Hubei province experienced an outbreak of cases characterized by unexplained low respiratory tract infections. The etiology of this illness is now attributed to the new coronavirus known as Severe Acute Respiratory Syndrome Coronavirus 2 (SARS-CoV-2). Evidence indicates that SARS-CoV-2 was transmitted from animals to humans at the Huanan Seafood Market in Wuhan [1]. By the 14th of January 2020 human-to-human transmission of the coronavirus was reported. Rapid worldwide spread followed this outbreak in China and, by March 11, 2020, The World Health Organization (WHO) proclaimed Coronavirus Disease 2019 (COVID-19), which is the infectious disease caused by the SARS-CoV-2 virus, a global pandemic [2]. By May $1^{\text {st }} 2020$, more than 4,893 people have died and 10,854 people have been hospitalized in the Netherlands due to COVID-19. [3].

Approximately 80 percent of COVID-19 patients experience respiratory symptoms [4]. Roughly twenty percent develop severe respiratory symptoms requiring hospital admission [5]. Of these, a quarter need invasive respiratory support. Multiple published case series and cohort studies suggest factors associated with poor clinical outcomes in COVID-19 disease including older age, hypertension and diabetes [4-6]. 
With the lack of high-quality evidence for any specific antiviral drug, symptomatic treatment with oxygen and, in severe cases, invasive mechanical ventilation remained the cornerstone of the treatment for COVID-19 at that time. As an intermediate step between conventional oxygen therapy and invasive mechanical ventilation, High-flow Nasal Cannula (HFNC) is widely used to treat severe respiratory infections. It allows non-invasive ventilation in a relatively comfortable way using high flow with preheated, humidified air containing large oxygen concentrations. Soon after the outbreak of the virus, HFNC therapy was implemented on our hospital wards for patients who failed on conventional high dose oxygen administration and were considered not eligible for invasive mechanical ventilation in the Intensive Care Unit (ICU) due to frailty, functional status, comorbidities or following a specific wish of the patient. In these cases, HFNC was seen as the last available strategy of oxygen administration on the wards. Nurses and staff were properly trained and surveillance was implemented by continuous remote monitoring systems measuring heart frequency and respiratory rate. So far, only two studies $[7,8]$ have described the clinical course of COVID-19 patients treated with HFNC. Large cohort studies assessing clinical outcomes are missing in this group.

This study describes the clinical course of a cohort of vulnerable elderly patients with respiratory failure despite conventional high dose oxygen administration, treated with HFNC for whom long standing invasive mechanical ventilation was not eligible due to functional status. The aim of this study was to investigate the hypothesis that HFNC therapy could serve as an appropriate alternative treatment for these patients. The primary outcome was survival. Furthermore, possible determinants associated with survival are suggested.

\section{Methods}

\section{Study design and population}

This was a retrospective, single center cohort study in the Maasstad Medical Centre, which is the largest (600-bed) non-academic teaching hospital in the Rotterdam area, the Netherlands. The study was approved by the Hospitals Medical Ethical Committee, application number W20.081.

The study included patients older than 18 years who were admitted to the hospital with a COVID-19 infection and severe respiratory insufficiency between the $9^{\text {th }}$ of March 2020 and $1^{\text {st }}$ of May 2020. SARSCoV-2 diagnoses were confirmed using PCR techniques on a nasopharyngeal swab with a Roche analyzer upon admission.

Mechanical ventilation in the ICU was declined in a portion of the admitted patients because of clinical frailty status, performance status or history of disease (e.g. severe cardiopulmonary conditions). These decisions were made in accordance with the patient and his or her relatives and were discussed on a daily basis in a multidisciplinary team together with Critical Care, Internal Medicine, Pulmonology and Palliative Care Specialists. During these meetings, performance scores, comorbidities, cognitive functioning, and frailty informed decision-making. When there was unanimous agreement that a patient 
was too frail for mechanical ventilation, HFNC was the only alternative treatment. All of these patients were included in the study. When starting HFNC, a flow of 60 liter per minute with a temperature of 37 degrees Celsius was used and further oxygen fractions were titrated based on oxygen saturation (SpO2 $>92 \%$ ) and respiratory rate (<25 per $\mathrm{min})$.

Data were collected using SQL Server Management Studio (version 18.3) from the electronic patient record (Chipsoft: Healthcare Information X-change). The hospital's data manager (GW) performed a first check after automatic extraction. A final check on the database was then performed by the two principal investigators (JvS and $\mathrm{MvH}$ ).

\section{Demographics, Medical history and Drug use}

Demographic data and medical history were extracted from the medical records. The following demographic data were extracted: age, gender, date of admission, days of hospital stay, body mass index (BMI) and survival. Comorbidities were scored, including hypertension (defined as the use of antihypertensive drugs), diabetes mellitus type 2 (defined as fasting plasma glucose level $\geq 6.1 \mathrm{mmol} / \mathrm{L}$ ), asthma (bronchodilator use and spirometry with reversibility), chronic obstructive pulmonary disease (COPD Gold classification), smoking (current or former), chronic kidney disease (eGFR $<60 \mathrm{ml} / \mathrm{min} / 1,73$ $\mathrm{m} 2$ ), malignancy (history of malignant neoplasm), occlusive peripheral arterial disease, ischemic heart disease (defined as obstructive coronary artery disease), non-ischemic heart disease, liver disease (radiological or pathological steatosis or cirrhosis) and the total number of comorbidities. Furthermore, out of hospital drug use (immunosuppressive drugs, ACE inhibitors and non-steroidal drugs) and in hospital drugs were scored (cefuroxime and azithromycin).

\section{Frailty assessment and clinical prediction scores}

The Clinical Frailty Score [9] ranging from 1 (very fit) to 9 (terminally ill) was used for clinical frailty assessment. In addition, WHO performance status score ranging from 1 (fully active) to 4 (completely disabled) [10] was extracted from the medical record. Sequential organ failure assessment scores (SOFA) were collected within 24 hours of admission for the prediction of clinical outcomes. Points for SOFA item 'mechanical ventilation' were assigned for patients on HFNC within the first 24 hours of admission.

\section{Signs and clinical parameters}

Clinical parameters were extracted from the medical record for every patient on admission, these include pulse rate, blood pressure, temperature, respiratory rate and oxygen saturation. Patients were asked about the presence and onset of the following symptoms: cough, dyspnea, weight loss, diarrhea and nausea.

\section{Laboratory values and Radiological findings}

For each patient blood examinations including hemoglobin, leukocyte count with differential count, platelet count, d-dimer, alanine transaminase (ALAT), aspartate transaminase (ASAT), creatine kinase (CK), lactate dehydrogenase (LDH), troponin T and ferritin levels were collected. These specific laboratory 
measures were chosen because most of them have already proved to be discriminating between mild and severe clinical courses [5]. A chest X-ray was performed upon admission in every patient. If there was a high clinical suspicion of pulmonary embolism with elevated d-dimer levels in absence of pulmonary infiltrates on chest x-ray, an additional computed tomography (CT) pulmonary angiogram was performed.

\section{High Flow Nasal Cannula therapy}

The number of days since admission was registered before the start of HFNC. Furthermore, flow (liters per minute), fraction of inspired oxygen ( $\mathrm{FiO} 2$ ) and reasons for failure of HFNC therapy were extracted from the medical record. FiO2 increase of ten percent in the first 24 hours were scored separately.

\section{Definitions}

Fever was defined as a tympanic temperature lower than 36 or greater than 38 degrees Celsius. Patients were considered infected if they were proven positive for SARS-CoV-2 using a nasopharyngeal PCR test.

Respiratory failure was defined as persisting hypoxemia despite maximum conventional oxygen administration e.g. saturation (SpO2) lower than 92\% despite maximum oxygen administration with a non-rebreathing mask (15 liters per minute). To assess the severity of Acute Respiratory Distress Syndrome (ARDS) Sp02/FiO2 ratios were calculated at start of HFNC therapy, as it was impossible to collect p02/FiO2 ratios for all patients and because SpO2/FiO2 can be considered equally sensitive and specific as compared to $\mathrm{PO} 2 / \mathrm{FiO} 2$ ratios[11].

\section{Statistical analysis}

Baseline data is presented as median (IQR) or $\mathrm{n}(\%)$. Differences between survivors and non-survivors were compared using Mann Whitney $U$ test for continuous data and Fisher's exact test for categorical data. P-values $<0.05$ were considered to be statistically significant. All statistical analysis were performed using The R Project for Statistical Computing (version 4.0.3) [12]. Variables with clinical relevance and in between group differences were used in a univariate logistic regression model to calculate odds ratios in order to assess factors associated with in hospital mortality. No multivariate analysis was performed because of high risk of overfitting the model due to the size of the cohort.

\section{Results}

\section{Demographics, Medical history and Drug use}

Between $9^{\text {th }}$ of March 2020 and $1^{\text {st }}$ of May 2020, 297 COVID-19 positive patients were admitted to our hospital. The patients had a median age of 62.5 years (52.5-78.0) and were predominantly male (58\%). 34 (11\%) COVID-19 patients received HFNC treatment. After excluding two patients that were still hospitalized during the analysis, 32 patients were included in the final cohort. There were no patients with missing baseline data. Baseline data is shown in Table 1. In the total cohort the median age was 79.0 years (74.5-83.0) and more than half were male (69\%). Median Body Mass Index (BMI) was 27.1 (26.3- 
31.4) and a median of three comorbidities were reported (3-4). Hypertension was the most frequently reported comorbidity (75\%) followed by diabetes mellitus type 2 (44\%). 16 percent of patients were current smokers and $19 \%$ had a history of tobacco use. With regards to medication use outside of the hospital, median number of drugs used for chronic purposes was seven (5-10).

\begin{tabular}{|c|c|c|c|c|c|}
\hline & & Total $(n=32)$ & $\begin{array}{c}\text { non-survivor }(\mathrm{n}= \\
24)\end{array}$ & $\begin{array}{l}\text { survivor }(\mathrm{n}= \\
8)\end{array}$ & $\begin{array}{r}\mathrm{p} \\
\text { value }\end{array}$ \\
\hline & & $\begin{array}{l}79.0(74.5- \\
83.0)\end{array}$ & 80.5(78.0-84.3) & $\begin{array}{l}69.5(65.5- \\
74.3)\end{array}$ & $<0.01$ \\
\hline 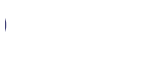 & & $22(69 \%)$ & $17(71 \%)$ & $5(62 \%)$ & 0.68 \\
\hline \multirow[t]{15}{*}{$e x$} & & $\begin{array}{l}27.1(26.3- \\
31.4) \\
\end{array}$ & $27.5(26.4-31.3)$ & $\begin{array}{l}27.0(26.2- \\
30.7) \\
\end{array}$ & 0.98 \\
\hline & Hypertension & $24(75 \%)$ & $22(92 \%)$ & $2(25 \%)$ & $<0.01$ \\
\hline & Diabetes & $14(44 \%)$ & $9(38 \%)$ & $5(62 \%)$ & 0.25 \\
\hline & Chronic Obstructive Lung Disease & $5(16 \%)$ & $5(21 \%)$ & 0 & 0.30 \\
\hline & Asthma & $3(9 \%)$ & $1(4 \%)$ & $2(25 \%)$ & 0.15 \\
\hline & Chronic Kidney Disease & $13(41 \%)$ & $12(50 \%)$ & $1(12 \%)$ & 0.11 \\
\hline & Malignancy & $11(34 \%)$ & $9(38 \%)$ & $2(25 \%)$ & 0.68 \\
\hline & Occlusive Peripheral Arterial Disease & $7(22 \%)$ & $4(17 \%)$ & $3(38 \%)$ & 0.33 \\
\hline & Non-ischemic Heart Disease & $11(34 \%)$ & $9(38 \%)$ & $2(25 \%)$ & 0.68 \\
\hline & Ischemic Heart Disease & $13(41 \%)$ & $10(42 \%)$ & $3(38 \%)$ & 1.00 \\
\hline & Neurovascular Disease & $6(19 \%)$ & $6(25 \%)$ & 0 & 0.30 \\
\hline & Liver Disease & $4(12 \%)$ & $2(8 \%)$ & $2(25 \%)$ & 0.25 \\
\hline & Total number of comorbidities & $3(3-4)$ & $3(3-4)$ & $3(3-3)$ & 0.50 \\
\hline & Current & $5(16 \%)$ & $4(17 \%)$ & $1(12 \%)$ & 1.00 \\
\hline & Former & $6(19 \%)$ & $5(21 \%)$ & $1(12 \%)$ & 1.00 \\
\hline \multirow[t]{2}{*}{ cores } & Clinical Frailty score & $4(3-6)$ & $4(4-6)$ & $4(4-6)$ & 0.44 \\
\hline & WHO Performance score & $2(2-4)$ & $2(2-4)$ & $2(2-3)$ & 0.68 \\
\hline :tion score & $\begin{array}{l}\text { SOFA score within } 24 \text { hours of } \\
\text { admission }\end{array}$ & $5(3-6)$ & $5(4-6)$ & $3.5(2-4,25)$ & 0.06 \\
\hline \multirow[t]{2}{*}{ dication } & Cefuroxim & $31(97 \%)$ & $23(96 \%)$ & $8(100 \%)$ & 1.00 \\
\hline & Azitromycin & $32(100 \%)$ & $24(100 \%)$ & $8(100 \%)$ & - \\
\hline \multirow[t]{4}{*}{ ! } & Immunosuppressives & $3(9 \%)$ & $2(8 \%)$ & $1(12 \%)$ & 1.00 \\
\hline & $N S A I D$ 'S & $2(6 \%)$ & $2(8 \%)$ & 0 & 1.00 \\
\hline & ACE-inhibitors & 9 (28\%) & 7 (29\%) & $2(25 \%)$ & 1.00 \\
\hline & Total number of chronic medications & $7(5-10)$ & $7(6-9)$ & $8(4-12)$ & 0.88 \\
\hline
\end{tabular}

Table 1 Baseline demographics

\section{Frailty assessment and clinical prediction scores}

The overall Clinical Frailty score was four (categorized as vulnerable) out of nine (3-6) compared to a WHO performance score of two out of four (2-4). SOFA scores within 24 hours of admission were 5 (4-6) for non-survivors and $3.5(2-4.25)$ for survivors $(p=0,06)$. See Table 1 for all data on the different scores. 
The median time in days between onset of symptoms and hospital admission was six (4-14). Nearly all patients reported cough (91\%) and dyspnea (84\%) on admission. 34 percent of the patients had fever and all patients were tachypneic during presentation in the emergency department. See Table 2 for a complete overview.

\begin{tabular}{l|l|l|l|l|r|}
\hline & & $\begin{array}{c}\text { Total }(\mathrm{n}= \\
\mathbf{3})\end{array}$ & \multicolumn{1}{|c|}{$\begin{array}{c}\text { non-survivor }(\mathrm{n}= \\
\mathbf{2 4})\end{array}$} & $\begin{array}{c}\text { survivor }(\mathrm{n}= \\
\mathbf{8})\end{array}$ & $\begin{array}{r}\mathrm{p} \\
\text { value }\end{array}$ \\
\hline & Cough & $29(91 \%)$ & $22(92 \%)$ & $7(88 \%)$ & 1.00 \\
\hline & Dyspnea & $27(84 \%)$ & $20(83 \%)$ & $7(88 \%)$ & 1.00 \\
\hline & Weight loss & $2(6 \%)$ & $1(4 \%)$ & $1(12 \%)$ & 0.44 \\
\hline & Diarrhea & $11(34 \%)$ & $8(33 \%)$ & $3(38 \%)$ & 1.00 \\
\hline & Nausea & $5(16 \%)$ & $4(17 \%)$ & $1(12 \%)$ & 1.00 \\
\hline & Respiratory Rate & $23(20-26)$ & $23(20-25)$ & $24(16-26)$ & 0.84 \\
\hline & $\begin{array}{l}\text { Respiratory Rate } \\
\text { >24 }\end{array}$ & $10(31 \%)$ & $6(25 \%)$ & $4(50 \%)$ & 0.22 \\
\hline & MAP>65 & $31(97 \%)$ & $23(96 \%)$ & $8(100 \%)$ & 1.00 \\
\hline symptom onset and admission & Heart rate & $92(77-102)$ & $92(77-102)$ & $91(78-99)$ & 0.85 \\
\hline ation (days) & $\begin{array}{l}\text { Fever }(>38 \text { or }<36 \\
\text { C) }\end{array}$ & $11(34 \%)$ & $9(38 \%)$ & $2(25 \%)$ & 0.69 \\
\hline
\end{tabular}

Table 2 Clinical symptoms and admission duration, Data are presented as n (\%) or median (IQR).

\section{Laboratory values and Radiological findings}

For an overview of laboratory values on admission and during hospital stay, see Table 3 . Most of the patients had radiological findings on chest x-rays upon admission. Out of these, bilateral pulmonary infiltrates were the most frequently found (72\%). Only $12(38 \%)$ patients underwent a CT-scan, pulmonary embolism was confirmed in five (45\%). 


\begin{tabular}{|c|c|c|c|c|c|}
\hline & & Total $(n=32)$ & $\begin{array}{c}\text { non-survivor }(\mathrm{n}= \\
24)\end{array}$ & $\begin{array}{c}\text { survivor }(\mathrm{n}= \\
8)\end{array}$ & $\begin{array}{r}p \\
\text { value }\end{array}$ \\
\hline \multicolumn{6}{|l|}{ Laboratory Markers } \\
\hline $\begin{array}{l}\text { White Bloodcell Count } \\
\left(\mathrm{x} 10^{\wedge} 9 / \mathrm{L}\right)\end{array}$ & & $7.0(5.2-10.7)$ & $7.6(6.2-10.9)$ & $5.2(5.0-6.3)$ & 0.04 \\
\hline $\begin{array}{l}\text { Absolute Lymfocyt Count } \\
\text { (x10^9/L) }\end{array}$ & & $1.0(0.7-1.4)$ & $0.9(0.6-1.4)$ & $1.1(1.0-1.4)$ & 0.27 \\
\hline Haemoglobin (mmol/L) & & $8.1(7.4-8.9)$ & $8.1(7.0-8.9)$ & $8.5(8.0-9.2)$ & 0.27 \\
\hline Platelet Count (x10^9/L) & & $211(180-281)$ & 207 (182-279) & $\begin{array}{l}242(182- \\
335)\end{array}$ & 0.60 \\
\hline Alanine aminotransferase (U/L) & & $31(25-40)$ & $30(25-39)$ & $34(29-40)$ & 0.36 \\
\hline $\begin{array}{l}\text { Aspartate aminotransferase } \\
(\mathrm{U} / \mathrm{L})\end{array}$ & & $59(45-68)$ & $54(39-68)$ & $60(59-67)$ & 0.28 \\
\hline Lactate dehydrogenase(U/L) & & $409(296-528)$ & $391(280-581)$ & $\begin{array}{l}424(395- \\
517)\end{array}$ & 0.56 \\
\hline D-Dimer (mg/L) & & $1.4(1.0-3.7)$ & $1.34(1.0-3.7)$ & $1.3(1.0-2.3)$ & 0.77 \\
\hline Procalcitonin $(\mu \mathrm{g} / \mathrm{L})$ & & $\begin{array}{l}0.17(0.12- \\
0.36) \\
\end{array}$ & $0.22(0.16-0.51)$ & $\begin{array}{l}0.12(0.1- \\
0.16)\end{array}$ & 0.03 \\
\hline Ferritin ( $\mu \mathrm{g} / \mathrm{L})$ & & $\begin{array}{l}695(373- \\
1313)\end{array}$ & $884(397-1438)$ & $\begin{array}{l}498(386- \\
794)\end{array}$ & 0.32 \\
\hline C-reactive protein $(\mathrm{mg} / \mathrm{L})$ & & $111(67-141)$ & $111(66-141)$ & $119(76-146)$ & 0.84 \\
\hline \multicolumn{6}{|l|}{ Radiological findings } \\
\hline \multirow[t]{3}{*}{ Chest X-Ray } & $\begin{array}{l}\text { Bilateral Pulmonary } \\
\text { Infiltration }\end{array}$ & $23(72 \%)$ & $16(67 \%)$ & 7 (88\%) & 0.39 \\
\hline & $\begin{array}{l}\text { Unilateral Pulmonary } \\
\text { Infiltration }\end{array}$ & $5(16 \%)$ & $5(21 \%)$ & $0(0 \%)$ & 0.30 \\
\hline & No Pulmonary Infiltration & 4 (12\%) & $3(12 \%)$ & $1(12 \%)$ & 1.00 \\
\hline Computed Tomography scan & & $12(38 \%)$ & 8 (33\%) & $4(50 \%)$ & 0.43 \\
\hline Pulmonary embolism & & $5(45 \%)$ & $4(57 \%)$ & $1(25 \%)$ & 0.55 \\
\hline
\end{tabular}

Table 3 Laboratory markers and radiological findings,.Data are presented as n (\%) or median (IQR).

\section{HFNC settings}

Median admission duration before HFNC initiation was 2.0 days (1.0-4.3). The median FiO2 at start was 0.60 (0.60-0.80) and the FiO2 max was 0.95 (0.80-0.95). Air flow was set at 60 liters per minute in all patients. Two-thirds of patients (66\%) required an increment in FiO2 of at least $10 \%$ in the first 24 hours after initiating the HFNC therapy. The initial median SPO2/FiO2 ratio was 157.5 (150-163.3), which is classified as a moderate ARDS. The most frequently reported reason for failure in the non-survivor group on HFNC was persistent hypoxemia (92\%). See Table 4 for a complete overview. 


\begin{tabular}{|c|c|c|c|c|c|}
\hline & & Total $(n=32)$ & $\begin{array}{c}\text { non-survivor }(\mathrm{n}= \\
24)\end{array}$ & survivor $(\mathrm{n}=8)$ & $\begin{array}{r}\mathrm{p} \\
\text { value }\end{array}$ \\
\hline \multirow[t]{4}{*}{ HFNC Settings } & Fio2 Start\% & $60(60-80)$ & $60(60-83)$ & $75(60-80)$ & 0.93 \\
\hline & Fio2 Мax $\%$ & $95(80-95)$ & $95(88-95)$ & $93(78-95)$ & 0.23 \\
\hline & Flow Start L/min & $60(60-60)$ & $60(60-60)$ & $60(60-60)$ & \\
\hline & Flow Max L/min & $60(60-60)$ & $60(60-60)$ & $60(60-60)$ & \\
\hline $10 \% \mathrm{FiO} 2$ increase in first 24 hours & & $21(66 \%)$ & $16(67 \%)$ & $5(62 \%)$ & 1.00 \\
\hline SPO2/FiO2 Ratio start HFNC & & $\begin{array}{l}157.5(150.0- \\
163.3)\end{array}$ & \begin{tabular}{|l|}
$157.5(148.8-$ \\
$162.1)$ \\
\end{tabular} & $\begin{array}{l}157.5(152.5- \\
164.2)\end{array}$ & 0.56 \\
\hline HFNC Duration (days) & & $2.5(1.0-4.3)$ & $2.0(1.0-3.0)$ & $9.5(4.8-17.5)$ & $<0.01$ \\
\hline $\begin{array}{l}\text { Duration between admission and HFNC } \\
\text { start (days) }\end{array}$ & & $2.0(1.0-4.0)$ & $2.0(1.0-4.0)$ & $3.5(1.8-4.2)$ & 0.29 \\
\hline \multirow[t]{2}{*}{ Reasons for HFNC failure } & $\begin{array}{l}\text { Persisting } \\
\text { hypoxemia }\end{array}$ & $22(69 \%)$ & $22(92 \%)$ & 0 & - \\
\hline & Toleration issues & $2(6 \%)$ & $2(8 \%)$ & 0 & \\
\hline
\end{tabular}

Table 4 HFNC settings and use. ,Data are presented as n (\%) or median (IQR).

\section{Survival and between group differences}

Overall survival rate in the HFNC cohort was $25 \%$. Between survivors and non-survivors, there was no statistically significant difference in BMI, comorbidities (including smoking), frailty and performance scores, medication use, HFNC settings, or most of the laboratory values and radiological findings.

However, between non-survivors and survivors, admission duration, HFNC therapy duration, age, hypertension, white blood cell count and procalcitonin levels were significantly different. Median admission duration was 15.2 days (12.3-25.9) in the survivor group compared to 4.9 (3.5-8.1) days in the non-survivor group $(p=0.0006)$ and median HFNC duration was 9.5 days $(4.8-17.5)$ in the survivor group and $2.0(1.0-3.0)$ in the non-survivor group $(\mathrm{p}=0.0012)$. Median age in the non-survivor group was 80.5 years (78-84.3) and 69.5 years $(65.5-74.3)$ in the survivor group $(p=0.0040)$. Furthermore, hypertension was a significantly more frequent comorbidity in the non-survivor group ( $92 \%$ vs $25 \% p=0.0008)$. Values of white blood cell count were significantly lower in the survivors $(7.6(6.2-10.9)$ vs $5.2(5.0-6.3) p=0.0385)$ as was procalcitonin $(0.22(0.16-0.51)$ vs $0.12(0.10-0.16) p=0.0335)$. Findings were confirmed for

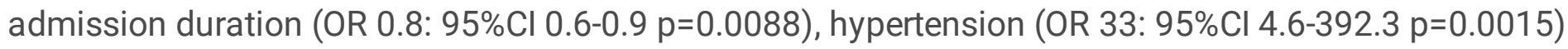
and age (OR 1.2: $95 \% \mathrm{Cl} 1.1-1.4 \mathrm{p}=0.0071)$ in our univariate analyses but not for laboratory values and HFNC duration.

\section{Discussion}


To the best of our knowledge, this is the first observational cohort study which describes the clinical course of a cohort of older COVID-19 patients with multiple comorbidities and frailty scores indicating vulnerability, treated with HFNC on the hospital wards because of failure of conventional administration with high volumes of oxygen, resulting in a survival rate of $25 \%$. This survival percentage is similar to patients with multiple comorbidities admitted to Dutch, European and Northern-American intensive care units in the same age group [13-15]. Thus, this study describes an alternative respiratory treatment strategy on the wards for vulnerable elderly COVID-19 patients for whom long standing invasive mechanical ventilation is not eligible due to frailty.

This study reports a much lower overall case rate survival than most reported survival rates on the clinical wards $[4,16,17]$. However, our cohort is a selection of frail patients with severe respiratory failure and high ARDS scores. Recently two other studies were published describing the successful use of HFNC in COVID-19 patients $[7,8]$. Contrary to these studies, we did not use HFNC therapy as an intermediate step between invasive mechanical ventilation and conventional oxygen therapy. Success rate of HFNC seems to be mostly dependent on the severity of pulmonary infection, with lower $\mathrm{PaO} 2 / \mathrm{FiO} 2$ ratios resulting in a higher chances of therapy failure. Wang et al. [8] described failure of HFNC in 63\% when PaO2/FiO2 was below $200 \mathrm{mmHg}$, comparable with this cohort. Previous studies have shown that vulnerability is associated with worse clinical outcomes including mortality and duration of hospitalization in non-COVID patients $[18,19]$. In line with our results, increasing age $[4,16,20]$ and hypertension $[4,5,20]$ are independent risk factors for mortality in COVID-19 positive patients. The latter finding is paradoxical since hypertension in frail older people without COVID-19 is not associated with higher mortality [21].

Regarding factors associated with poor outcomes, only procalcitonin and leukocyte count were found to be associated with higher mortality, this is likely the results of our small sample size. Earlier risk factor defining studies on COVID-19 patients found that neutrophilia, raised lactate dehydrogenase, leukocyte counts and raised ASAT are all associated with higher disease burden [4].

In line with the small case series on HFNC in COVID-19 patients published by Geng et al. [7] we have experienced HFNC to be both patient and staff friendly. Staff reported HFNC machines to be easy to use while patients reported relatively high comfort breathing humidified and preheated air. The benefits of patient tolerance combined with more reliable delivery of FiO2 due to dead space flushing makes HFNC an excellent method of oxygen supply [22]. Furthermore, as described by Marini et al. early initiation of HFNC can reduce inspiratory effort resulting in lowering pulmonary trans-vascular pressures and can protect lungs from patient self-inflicted lung injury [23]. The combination of the tolerability, especially for long ventilation duration, the reduced nursing workload, the availability and previous literature describing significantly lower 90-day mortality in favor of HFNC in acute hypoxemic respiratory failure as compared to other forms of NIV like Continuous Positive Airway Pressure (CPAP) or Bilevel Positive Airway Pressure (BiPAP) therapy led to the decision to use HFNC as the therapy of choice [24]. As a result, even in patients who failed HFNC we did not use CPAP or BiPAP as an alternative treatment. 
When HFNC was introduced in our hospital, a comment was raised about potential safety issues with regards to aerosol and viral spread with non-invasive mechanical ventilation like HFNC. All of the staff operating HFNC machines used Filtering Facepiece Particles-2 (FFP-2) masks, gowns, gloves and eye protection. Available literature did not reveal any evidence of increased risk of contamination while working with HFNC $[25,26]$. Only one retrospective study is available describing the infection rates of SARS-CoV-1 in hospital workers operating HFNC machines. As compared to tracheal intubation (35\%) and NIV (38\%), HFNC seems to be the safest option with a lower risk of infection (8\%) [27]. Our study was not designed to address these potential safety hazards, but based on infection rates amongst hospital staff no concerns about using HFNC came to light.

\section{Limitations}

This study has several limitations. First, randomizing between HFNC and continuing standard oxygen supply, which is the only reasonable alternative active treatment on the wards, was considered to be ethically inappropriate since failure occurred on conventional oxygen supply. This means that no conclusions can be drawn regarding survival and clinical performance between HFNC therapy and conventional oxygen administration in COVID-19 patients with similar characteristics. Second, no conclusion can be made about survival if our patients would be admitted to the ICU for invasive mechanical ventilation instead of receiving HFNC treatment on the ward. Thirdly and lastly, due the relatively small cohort, there was a risk of underfitting and it was difficult to demonstrate differentiating factors between survivors and non-survivors in our population. This risk was minimized by including all of our frail HFNC patients. A large multicenter prospective study could further improve generalizability, confirm our results, and identify factors for success or failure of HFNC therapy in frail patients on the ward.

\section{Conclusions}

This retrospective cohort study shows that HFNC is a promising respiratory treatment strategy on the wards for vulnerable elderly COVID-19 patients for whom prolonged mechanical ventilation is beyond limits.

\section{List Of Abbreviations}

HFNC: High-flow nasal cannula

ICU: Intensive Care Unit

SARS-CoV-2: Severe Acute Respiratory Syndrome Coronavirus 2

COVID-19: Coronavirus disease 2019

BMl: Body Mass Index

Page $11 / 15$ 
COPD: Chronic Obstructive Pulmonary Disease

eGFR: estimated Glomerular Filtration Rate

ACE: Angiotensine Converting Enzyme

ALAT: Allanine transaminase

ASAT: Aspartate transaminase (ASAT)

CK: Creatine kinase

LD: Lactate dehydrogenase

CT: Computed tomography

FiO2: Fraction of inspired oxygen

ARDS: Acute Respiratory Distress Syndrome

NIV: Noninvasive Ventilation

SOFA: Sequential Organ Failure

FFP-2: Filtering Facepiece Particles-2

\section{Declarations}

\section{Ethics approval and consent to participate}

This study was approved by the Hospitals Medical Ethical Committee (Medical Research Ethics Committees United, reference L2019023) , application number W20.081.

\section{Consent for publication}

Not applicable.

\section{Availability of data and materials}

The datasets used and/or analysed during the current study are available from the corresponding author on reasonable request

\section{Competing interests}

The authors declare that they have no competing interests.

\section{Funding}


This research did not receive any specific grant from funding agencies in the public, commercial, or notfor-profit sectors.

\section{Authors' Contributions}

JS and $\mathrm{MH}$ invented the study and were responsible for integrity of the database. All authors were responsible for treatment of the patients, collecting clinical and additional data and for writing the manuscript. All authors approved the final version after reviewing

\section{Acknowledgements}

We thank Geeke van Waverijn for data extraction and preparation. We thank Evelien Oostdijk and Rob Zwinkels for the critical reading of the manuscript.

\section{References}

1. Zhu N, Zhang D, Wang W, Li X, Yang B, Song J, Zhao X, Huang B, Shi W, Lu R et al: A Novel Coronavirus from Patients with Pneumonia in China, 2019. N Engl J Med 2020, 382(8):727-733.

2. Wang D, Hu B, Hu C, Zhu F, Liu X, Zhang J, Wang B, Xiang H, Cheng Z, Xiong Y et al: Clinical Characteristics of 138 Hospitalized Patients With 2019 Novel Coronavirus-Infected Pneumonia in Wuhan, China. JAMA 2020.

3. Environment NIfPHat: Current information about COVID-19 (novel coronavirus). In. Edited by Health Mo: Ministry of Health; 2020.

4. Du RH, Liang LR, Yang CQ, Wang W, Cao TZ, Li M, Guo GY, Du J, Zheng CL, Zhu Q et al: Predictors of mortality for patients with COVID-19 pneumonia caused by SARS-CoV-2: a prospective cohort study. Eur Respir J 2020, 55(5).

5. Cevik M, Bamford C, Ho A: COVID-19 pandemic - A focused review for clinicians. Clin Microbiol Infect 2020.

6. Tolksdorf K, Buda S, Schuler E, Wieler LH, Haas W: Influenza-associated pneumonia as reference to assess seriousness of coronavirus disease (COVID-19). Euro Surveill 2020, 25(11).

7. Geng S, Mei Q, Zhu C, Yang T, Yang Y, Fang X, Pan A: High flow nasal cannula is a good treatment option for COVID-19. Heart Lung 2020.

8. Wang K, Zhao W, Li J, Shu W, Duan J: The experience of high-flow nasal cannula in hospitalized patients with 2019 novel coronavirus-infected pneumonia in two hospitals of Chongqing, China. Ann Intensive Care 2020, 10(1):37.

9. Rockwood K, Song X, MacKnight C, Bergman H, Hogan DB, McDowell I, Mitnitski A: A global clinical measure of fitness and frailty in elderly people. CMAJ 2005, 173(5):489-495.

10. Oken MM, Creech RH, Tormey DC, Horton J, Davis TE, McFadden ET, Carbone PP: Toxicity and response criteria of the Eastern Cooperative Oncology Group. Am J Clin Oncol 1982, 5(6):649-655. 
11. Bilan N, Dastranji A, Ghalehgolab Behbahani A: Comparison of the spo2/fio2 ratio and the pao2/fio2 ratio in patients with acute lung injury or acute respiratory distress syndrome. $J$ Cardiovasc Thorac Res 2015, 7(1):28-31.

12. R Core Team: R: A Language and Environment for Statistical Computing. In., 4.0.3 edn. Vienna, Austria: R Foundation for Statistical Computing; 2020.

13. Evaluatie SNIC: COVID-19 in Dutch Intensive Care Units; Patient characteristics and outcomes compared with pneumonia patients in the ICU from 2017-2019. In.; 2020.

14. Grasselli G, Zangrillo A, Zanella A, Antonelli M, Cabrini L, Castelli A, Cereda D, Coluccello A, Foti G, Fumagalli R et al: Baseline Characteristics and Outcomes of 1591 Patients Infected With SARS-CoV2 Admitted to ICUs of the Lombardy Region, Italy. JAMA 2020.

15. Auld SC, Caridi-Scheible M, Blum JM, Robichaux C, Kraft C, Jacob JT, Jabaley CS, Carpenter D, Kaplow R, Hernandez-Romieu AC et al: ICU and Ventilator Mortality Among Critically III Adults With Coronavirus Disease 2019. Crit Care Med 2020.

16. Zhou F, Yu T, Du R, Fan G, Liu Y, Liu Z, Xiang J, Wang Y, Song B, Gu X et al: Clinical course and risk factors for mortality of adult inpatients with COVID-19 in Wuhan, China: a retrospective cohort study. Lancet 2020, 395(10229):1054-1062.

17. Liang WH, Guan WJ, Li CC, Li YM, Liang HR, Zhao Y, Liu XQ, Sang L, Chen RC, Tang CL et al: Clinical characteristics and outcomes of hospitalised patients with COVID-19 treated in Hubei (epicenter) and outside Hubei (non-epicenter): A Nationwide Analysis of China. Eur Respir J 2020.

18. So RKL, Bannard-Smith J, Subbe CP, Jones DA, van Rosmalen J, Lighthall GK, investigators Ms: The association of clinical frailty with outcomes of patients reviewed by rapid response teams: an international prospective observational cohort study. Crit Care 2018, 22(1):227.

19. Brummel NE, Bell SP, Girard TD, Pandharipande PP, Jackson JC, Morandi A, Thompson JL, Chandrasekhar R, Bernard GR, Dittus RS et al: Frailty and Subsequent Disability and Mortality among Patients with Critical IIIness. Am J Respir Crit Care Med 2017, 196(1):64-72.

20. Zangrillo A, Beretta L, Scandroglio AM, Monti G, Fominskiy E, Colombo S, Morselli F, Belletti A, Silvani $\mathrm{P}$, Crivellari $\mathrm{M}$ et al: Characteristics, treatment, outcomes and cause of death of invasively ventilated patients with COVID-19 ARDS in Milan, Italy. Crit Care Resusc 2020.

21. Todd OM, Wilkinson C, Hale M, Wong NL, Hall M, Sheppard JP, McManus RJ, Rockwood K, Young J, Gale $\mathrm{CP}$ et al: Is the association between blood pressure and mortality in older adults different with frailty? A systematic review and meta-analysis. Age Ageing 2019, 48(5):627-635.

22. Spoletini G, Hill NS: High-flow nasal oxygen versus noninvasive ventilation for hypoxemic respiratory failure: Do we know enough? Ann Thorac Med 2016, 11(3):163-166.

23. Marini JJ, Gattinoni L: Management of COVID-19 Respiratory Distress. JAMA 2020.

24. Frat JP, Thille AW, Mercat A, Girault C, Ragot S, Perbet S, Prat G, Boulain T, Morawiec E, Cottereau A et al: High-flow oxygen through nasal cannula in acute hypoxemic respiratory failure. $\mathrm{N} \mathrm{Engl} \mathrm{J} \mathrm{Med}$ 2015, 372(23):2185-2196. 
25. Tran K, Cimon K, Severn M, Pessoa-Silva CL, Conly J: Aerosol generating procedures and risk of transmission of acute respiratory infections to healthcare workers: a systematic review. PLOS One 2012, 7(4):e35797.

26. Loh NW, Tan Y, Taculod J, Gorospe B, Teope AS, Somani J, Tan AYH: The impact of high-flow nasal cannula (HFNC) on coughing distance: implications on its use during the novel coronavirus disease outbreak. Can J Anaesth 2020.

27. Raboud J, Shigayeva A, McGeer A, Bontovics E, Chapman M, Gravel D, Henry B, Lapinsky S, Loeb M, McDonald LC et al: Risk factors for SARS transmission from patients requiring intubation: a multicentre investigation in Toronto, Canada. PLoS One 2010, 5(5):e10717.

\section{Supplementary Files}

This is a list of supplementary files associated with this preprint. Click to download.

- STROBEchecklist.pdf 